\title{
A Cafeicultura no Sul de Minas e em Nepomuceno-MG entre as Décadas de 1950 e $1990^{i}$
}

\author{
The Coffee Sector in the South of Minas and in Nepomuceno-MG \\ between the 1950s and 1990s
}

\section{La Economía Cafetera en Sur de Minas y en Nepomuceno-MG entre los Años 1950 y 1990}

\author{
Lucas Guedes Vilas Boas ${ }^{1}$
}

https://orcid.org/0000-0003-3189-0520

\begin{abstract}
RESUMO: A cafeicultura ganhou destaque na economia do Sul de Minas Gerais no século XIX. Na primeira metade do século XX tornou-se a atividade econômica de maior relevância em muitos municípios sul-mineiros. Considerando a importância do setor cafeeiro para a região Sul de Minas e o município de Nepomuceno, o artigo discute os principais elementos de sua cafeicultura entre as décadas de 1950 e 1990. Os procedimentos metodológicos adotados foram a pesquisa bibliográfica e a análise documental. Entre os decênios de 1950 e 1980, o Estado brasileiro, por intermédio de diversos órgãos, incentivou a modernização da cafeicultura sul-mineira, a adesão ao pacote tecnológico oriundo da Revolução Verde, a substituição dos cafezais pouco produtivos e a fundação de cooperativas privadas. Especialmente a partir do fim dos anos 1980 e início da década de 1990, as políticas neoliberais chegaram à cafeicultura e o papel estatal no setor foi diminuído. As cooperativas privadas passaram a desempenhar a função antes exercida pelo Estado. Destarte, houve aumento da volatilidade dos preços venais do café, prejudicando principalmente os pequenos cafeicultores.
\end{abstract}

PALAVRAS-CHAVE: Cafeicultura. Sul de Minas. Nepomuceno-MG.

ABSTRACT: Coffee sector gained prominence in the economy in the South of Minas Gerais in the 19th century. In the first half of the 20th century, it became the most relevant economic activity in many municipalities in the state of Minas Gerais. Considering the importance of the coffee sector for the Southern region of Minas and the municipality of Nepomuceno, the article discusses the main elements of its coffee culture between 1950s and 1990s. The methodological procedures adopted were bibliographic research and document analysis. Between the 1950s and 1980s, the Brazilian State, through various agencies, encouraged the modernization of coffee production in the South of Minas Gerais, adherence to the technologic package resulting from the Green Revolution, the replacement of low productivity coffee plantations and the foundation of private cooperatives. Especially from the late 1980s and early 1990s, neoliberal policies came to coffee culture and the state's role in the sector was diminished. Private Cooperatives started to perform the function previously exercised by the State. Thus, there was an increase in the volatility of coffee prices, mainly affecting small coffee producters.

\footnotetext{
1 Doutor em Geografia - UFMG. Professor Adjunto - CEFET-MG. E-mail: lucasguedes@cefetmg.br.
} 
KEYWORDS: Coffee sector. Sul de Minas. Nepomuceno-MG.

RESUMEN: La actividad cafetera ganó prominencia en la economía del sur de Minas Gerais en el siglo XIX. En la primera mitad del siglo XX, se convirtió en la actividad económica más relevante en muchos municipios sur-mineros. Considerando la importancia del sector cafetero para la región sur de Minas y el municipio de Nepomuceno, el artículo discute los principales elementos de su economía cafetera entre los años 1950 y 1990. Los procedimientos metodológicos adoptados fueron la investigación bibliográfica y el análisis de documentos. Entre los años 1950 y 1980, el Estado brasileño, a través de varios órganos, estimuló la modernización de la actividad cafetera sur-minera, la adhesión al paquete tecnológico oriundo de la Revolución Verde, la sustitución de los cafetales poco productivos y la fundación de cooperativas privadas. Especialmente desde finales de los años 1980 y principios de los 1990, las políticas neoliberales llegaron a la actividad cafetera y el papel estatal en el sector disminuyó. Las cooperativas privadas comenzaron a realizar la función antes ejercida por el Estado. Así, hubo aumento de la volatilidad de los precios de venta del café, perjudicando principalmente a los pequeños caficultores.

PALABRAS-CLAVE: Economía cafetera. Sul de Minas. Nepomuceno-MG.

\section{INTRODUÇÃO}

A propriedade fundiária privada prevalece, com relação à área ocupada, no Brasil (OLIVEIRA, 2007). Tal característica é fundamental à hegemonia das ações típicas do modo de produção capitalista no campo pois, de acordo com Marx (1983), a inserção do capital no ramo agrícola depende da propriedade privada da terra, a qual propicia a disseminação de diversas práticas e relações capitalistas de produção e de trabalho no campo e na agricultura.

O modo histórico-materialista de pensar a geografia rompe com a estrutura tripartite natureza-homem-economia, baseia-se no conceito de trabalho como mediador das relações e entende a relação homem-meio como uma relação de troca metabólica, na qual o homem se apropria da natureza (MOREIRA, 2007). Assim, o artigo confere ênfase às mudanças vivenciadas no processo produtivo da cafeicultura sul-mineira e nepomucenense no período estudado. Entende-se que a agricultura e, particularmente, a cafeicultura, estão inseridas e subordinadas ao modo de produção capitalista por intermédio de vários processos, como: a adoção das tecnologias oriundas da Revolução Verde, a integração ao agronegócio e às redes geográficas de produção e comercialização de café, a disseminação de práticas monocultoras, o atendimento às demandas dos mercados internacionais, a exploração do trabalho e sua intensificação por meio da remuneração proporcional à produtividade lograda.

No decênio de 1950, a cafeicultura já estava consolidada como a principal atividade econômica da região Sul de Minas. À época, o keynesianismo ainda era pujante e, por conseguinte, era expressiva a intervenção estatal na economia. O keynesianismo é uma 
política econômica que se disseminou após a Crise de 1929. Baseia-se em profunda intervenção estatal na economia e na intensa atuação nos momentos de crise, com ações em prol do bem-estar social e em setores sociais básicos, como saúde e educação. Os Estados keynesianos investem na criação de indústrias estatais, na diminuição das importações e, consequentemente, na redução da dependência em relação ao exterior. Também efetivam ações para equilibrar a oferta e a demanda em determinados setores.

As ações do Estado no setor cafeeiro ocasionaram significativas consequências, as quais são discutidas a seguir. Na transição entre as décadas de 1980 e 1990, o neoliberalismo domina a economia e a cafeicultura em território brasileiro. Destarte, o artigo discute a cafeicultura sul-mineira e nepomucenense entre os decênios de 19501990.

O município de Nepomuceno está localizado na região de planejamento Sul de Minas (Figura 01) e apresentava uma população estimada de 26.769 habitantes em 2019 (IBGE, 2019a). Em 2010, 77,47\% da população nepomucenense era urbana, enquanto $22,53 \%$ era rural (IBGE, 2010). No ano de 2017, o PIB municipal foi de $R \$ 444.409 .000,00$ e a agropecuária gerou $\mathrm{R} \$ 106.339 .000,00$ (25,69\% do total) (IBGE, 2019b). A agricultura possui relevância na economia municipal, com destaque para a cafeicultura, a qual logrou destaque na conjuntura local desde a primeira metade do século XX (VILAS BOAS, 2016). Em 2018, foram produzidas 18.809 toneladas de café no município, cujo valor total estimado ficou em $R \$ 139.187 .000,00$ (IBGE, 2019b).

O ínterim analisado abrange o capitalismo financeiro e a Terceira Divisão Internacional do Trabalho (Terceira DIT), na qual os países subdesenvolvidos produzem matérias-primas, commodities e mercadorias industriais de baixo valor agregado, enquanto os desenvolvidos fabricam produtos industrializados de alto valor agregado e fornecem alta tecnologia e investimentos aos demais. Neste contexto, corporações transnacionais e multinacionais se aproveitam da mão de obra barata, das frágeis legislações trabalhistas e ambientais, da abundância de matérias-primas e de outras vantagens locacionais apresentadas pelos países subdesenvolvidos (HARVEY, 2011; SANTOS, 2005). Tal dinâmica impacta significativamente as balanças comerciais dos países, ocasionando expressivo déficit naqueles mais pobres.

A divisão territorial do trabalho é consequência da divisão internacional do trabalho e ocasiona uma hierarquia entre os lugares. Assim, as atividades e os recursos se distribuem desigualmente pelo espaço geográfico. Por conseguinte, determinadas regiões centralizam e concentram as atividades de alguns setores. As corporações transnacionais e multinacionais do agronegócio desenvolvem uma logística que favorece a especialização produtiva e as monoculturas em áreas específicas. Quando a divisão geral e social do trabalho se acirra, amplia-se também a divisão territorial do trabalho (SANTOS, 2005). 
Figura 01 - Localização do Município de Nepomuceno-MG
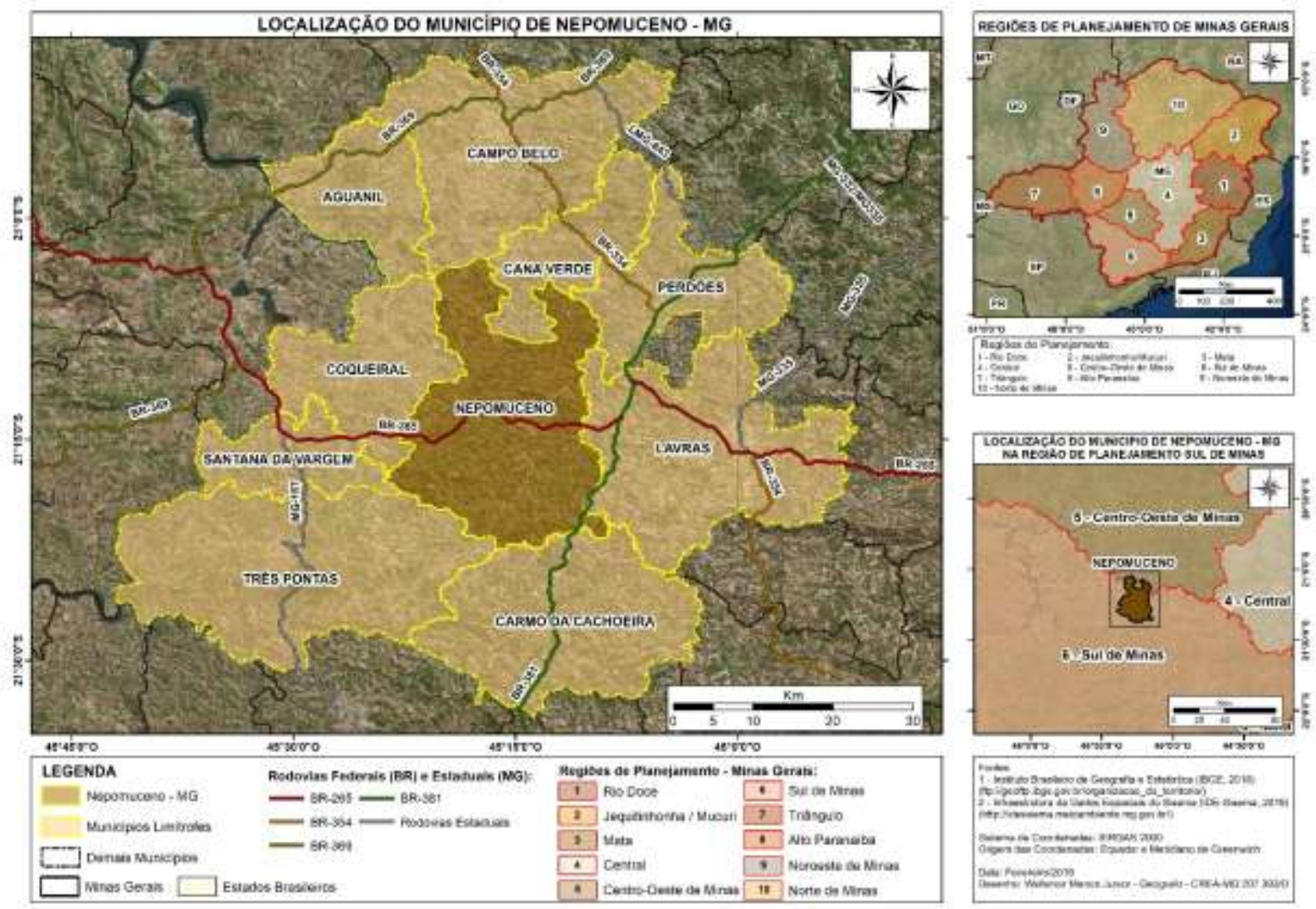

Fonte: dados da pesquisa, elaborado por: Waltencir Menon Júnior (2019).

As atividades produtivas do Brasil respondem e são subordinadas a demandas internacionais. Em virtude disso, o país se consolidou como exportador de commodities. A produção de monoculturas voltadas à exportação corrobora o papel submisso do Brasil na Terceira DIT, pois o Estado atende a exigências externas, desenvolvendo infraestruturas e programas de crédito para a agropecuária. Nos anos 1960 e 1970, o Brasil experimenta uma modernização agrícola que o alça ao posto de um dos maiores produtores mundiais de grãos (PEREIRA, 2010). Consequentemente, no âmbito da divisão territorial do trabalho e da especialização produtiva, a região Sul de Minas e, particularmente, o município de Nepomuceno, são áreas produtoras de café, inseridas em redes nacionais e internacionais de produção e comercialização da rubiácea.

Os procedimentos metodológicos empregados foram a pesquisa bibliográfica e a análise documental, na qual foram analisados dados e publicações disponibilizados pela Cooxupé - Cooperativa Regional dos Cafeicultores em Guaxupé (2018) e pelo Instituto Brasileiro de Geografia e Estatística (IBGE). 


\section{A AÇÃO DO ESTADO NA AGRICULTURA SUL-MINEIRA E A CONJUNTURA AGRÁRIA NEPOMUCENENSE ENTRE OS DECÊNIOS DE 1950 E 1980}

A partir do decênio de 1950, com as políticas keynesianas do governo Vargas, houve notória intervenção estatal na cafeicultura, sobretudo por intermédio do Instituto Brasileiro do Café (IBC), fundado em 1952 (COULIS, 2011; DELFIM NETTO, 2009). Sua principal função era regular a produção e o comércio do café em território nacional. O IBC adquiria a produção cafeeira sem maiores preocupações com a qualidade dos grãos. Além disso, na maioria das situações, pagava um preço superior ao pago no mercado internacional, tornando muito dispendiosa sua política de regulação dos estoques. Alguns programas do IBC aplicados no sul de Minas Gerais propiciaram a modernização de sua cafeicultura, impulsionando a disseminação das lavouras (SOUZA, 2006; VALE; CALDERARO; FAGUNDES, 2014).

Ao fim da Segunda Guerra Mundial, houve relativa escassez de mão de obra destinada à cafeicultura. Em partes, a redução da oferta de força de trabalho foi ocasionada pelas péssimas condições de trabalho vigentes (ARAÚJO FILHO, 1992). Em 1955, a cafeicultura e a pecuária bovina eram as principais atividades econômicas de Nepomuceno, mas o cultivo de arroz e milho, assim como a suinocultura, também se destacavam na economia local (Tabelas 01 e 02). Nesse ano, a produção municipal de café foi de 120 mil sacas (IBGE, 1959).

Tabela 01 - Produção Agrícola do Município de Nepomuceno-MG em 1955

\begin{tabular}{lcc}
\hline Gênero & Área (em hectares) & Produção Total (em arrobas) \\
Café & 14.080 & 440.000 \\
Arroz & 3.200 & 272.000 \\
Milho & 2.160 & 152.960 \\
Fumo & 95 & 2.375 \\
Outros & 304 & Sem dados \\
Total & 19.839 & Sem dados \\
\hline
\end{tabular}

Fonte: IBGE (1959).

Tabela 02 - Pecuária do Município de Nepomuceno-MG em 1955 - Número de Cabeças por Espécies

\begin{tabular}{lc}
\hline Espécie & Quantidade de Cabeças \\
Bovinos & 11.000 \\
Suínos & 4.500 \\
Equinos & 3.500 \\
Caprinos & 900 \\
Ovinos & 600 \\
Muares & 530 \\
\hline
\end{tabular}

Fonte: IBGE (1959). 
Nas décadas de 1950 e 1970, o governo brasileiro financiou crédito para que os agricultores expandissem suas lavouras cafeeiras, promovendo o crescimento da cafeicultura, sobretudo em Minas Gerais (WATSON, ACHINELLI, 2008; COULIS, 2011). Neste período, diversos estudos foram realizados com o intuito de ampliar a produtividade das lavouras. Assim, a partir do decênio de 1960, houve em terras capixabas gradativa substituição do cultivo do café arábica pelo conilon, o qual apresentou melhor adaptação ao clima espírito-santense, promovendo o êxito da cafeicultura estadual (IBGE, 2016).

O governo mineiro inaugurou uma sede da Associação de Crédito e Assistência Rural (ACAR) no município de Nepomuceno em 1958. Os principais objetivos da ACAR eram o desenvolvimento da agricultura mineira e a inserção de novas técnicas que aumentassem a produtividade no campo. No ano de 1975, a ACAR foi extinta e substituída pela Empresa de Assistência Técnica e Extensão Rural do Estado de Minas Gerais (EMATER-MG), entidade que nos tempos hodiernos atua em Nepomuceno (ANDRADE, 1994; VACA, 2015).

Até a década de 1960, foi comum o regime de colonato no sul de Minas, no qual o trabalhador recebia uma quantia predeterminada pelo número de cafeeiros cuidados e uma remuneração diária por atividades como a poda e a adubação, além de um valor pago por produtividade durante a colheita. Ademais, podia dispor de parcela das terras ocupadas para a pecuária e o plantio de outros víveres, especialmente para autoconsumo (CASTILHO, 2009; FREDERICO, 2017). Em 1960, o café era responsável por mais da metade das exportações brasileiras, sendo o principal produto da economia nacional. Já em 1962, o primeiro Acordo Internacional do Café (AIC) foi firmado, cujo objetivo era a regulação dos preços. Entre 1962 e 1973, o programa foi exitoso, com pouca oscilação nos preços venais, beneficiando os principais países produtores, como o Brasil (COULIS, 2011; FREDERICO, 2017).

Em território brasileiro, o IBC, através do Grupo Executivo de Racionalização da Cafeicultura (GERCA), estimulou a erradicação de milhões de cafeeiros em Minas Gerais, sobretudo na região sul (Figura 02). Na década de 1960, os pés mais antigos e malconservados foram os primeiros a serem destruídos.

A eliminação de cafeeiros compôs um pacote de medidas estatais cujo intuito era a amenização dos efeitos da crise de superprodução. Os preços do café brasileiro experimentaram um momento de queda, especialmente após a grande safra no Paraná em 1961. A destruição de praticamente metade dos cafeeiros do país ampliou o desemprego rural em âmbito nacional e estadual, uma vez que a cafeicultura absorvia parcela expressiva da força de trabalho rural (ANDRADE, 1994; COELHO, 2012). Quanto ao assunto, o Quadro 01 sintetiza as principais intervenções do Estado na cafeicultura brasileira entre 1950 e 1990. 
Figura 02 - Cafeeiros Erradicados (em 1.000 pés) no Sul de Minas Gerais no Quinquênio 1962-1966

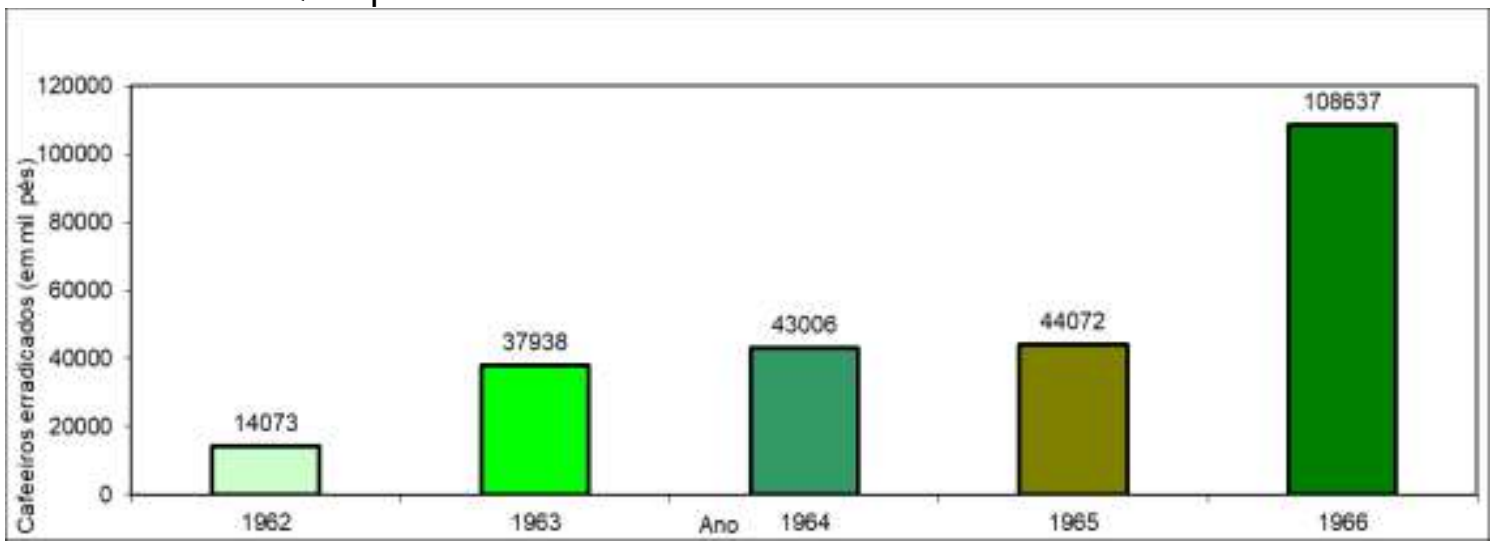

Fonte: Andrade (1994).

Quadro 01 - Ações das Principais Instituições e Programas Estatais na Cafeicultura Brasileira - Período: 1950-1990

\begin{tabular}{|l|c|l|}
\hline \multicolumn{1}{|c|}{ Instituição/Programa } & Período de Atuação & \multicolumn{1}{c|}{ Missões } \\
\hline $\begin{array}{l}\text { Instituto Brasileiro do } \\
\text { Café (IBC) }\end{array}$ & $1952-1990 / 91$ & $\begin{array}{l}\text { Regular a produção, o comércio e os } \\
\text { estoques do café brasileiro; aumentar a } \\
\text { produtividade cafeeira e fomentar a } \\
\text { fundação de cooperativas }\end{array}$ \\
\hline $\begin{array}{l}\text { Grupo Executivo de } \\
\text { Racionalização da } \\
\text { Cafeicultura (GERCA) }\end{array}$ & $1961-1990 / 91$ & $\begin{array}{l}\text { Racionalizar a produção cafeeira } \\
\text { nacional, erradicar os cafeeiros } \\
\text { improdutivos e conceder crédito para a } \\
\text { ampliação da produtividade agrícola por } \\
\text { meio do uso de insumos agrícolas }\end{array}$ \\
\hline $\begin{array}{l}\text { Planos de Renovação e } \\
\text { Revigoramento de } \\
\text { Cafezais (PRRCs) }\end{array}$ & $\begin{array}{l}\text { Renovar os cafezais brasileiros, } \\
\text { subsidiar crédito para os cafeicultores, } \\
\text { aumentar a produtividade cafeeira e } \\
\text { fornecer assistência técnica aos } \\
\text { cafeicultores }\end{array}$ \\
\hline $\begin{array}{l}\text { Sistema Nacional de } \\
\text { Crédito Rural (SNCR) }\end{array}$ & $1970 / 71-1981$ & $\begin{array}{l}\text { Subsidiar a compra de insumos } \\
\text { agrícolas, incentivar o plantio de } \\
\text { variedades mais produtivas e construir } \\
\text { infraestrutura para armazenamento e } \\
\text { produção }\end{array}$ \\
\hline
\end{tabular}

Fonte: Andrade (1994), Rollo (2009), Coulis (2011), Carvalho (2013) e Frederico (2017).

A partir do decênio de 1960, houve a disseminação de uma cafeicultura técnicocientífica no sul de Minas Gerais, com importante papel estatal, exercido através do IBC/GERCA. Parcela considerável da infraestrutura de armazenamento de café construída por meio do organismo federal ainda é utilizada, com destaque para os armazéns situados em Varginha. A formação de complexos agroindustriais, os Planos de Renovação e Revigoramento de Cafezais (PRRCs) e a introdução de técnicas oriundas da Revolução Verde na agricultura sul-mineira favoreceram sua inserção no meio técnico-científico (CARVALHO, 2013; COELHO, 2012; FREDERICO, 2017). Destarte, a década de 1960 
experimentou notável crescimento da cafeicultura em escala nacional, estadual e regional (ROLLO, 2009).

Os complexos agroindustriais integram os setores primário, secundário e terciário em todo o processo produtivo, pois vinculam a indústria a montante (fabricante de insumos agrícolas), a agropecuária e a indústria a jusante (responsável pelo processamento/transformação da matéria-prima), além de se incumbirem da comercialização dos produtos finais. As políticas instituídas pelo Estado brasileiro favoreceram sua disseminação a partir dos anos 1960 e 1970, pois estimularam o surgimento de indústrias voltadas à produção de máquinas agrícolas, fertilizantes químicos e agrotóxicos (MÜLLER, 1982). As ações estatais subsidiaram a aquisição de insumos agrícolas e providenciaram infraestrutura para a especialização produtiva, facilitando a propagação das monoculturas (ANDRADE, 1994; ROLLO, 2009), como a cafeicultura no Sul de Minas Gerais.

Em 1963, Alberto Correia Lima assumiu a Prefeitura Municipal de Nepomuceno, apoiado pelo então governador Magalhães Pinto. Ante um contexto de modernização da cafeicultura através dos investimentos fomentados pelo IBC, seu mandato foi marcado por muitos investimentos no campo nepomucenense, sobretudo com a construção de escolas rurais (VACA, 2015). No ano de 1965, foi criado o Sistema Nacional de Crédito Rural (SNCR), órgão estatal cujas principais funções eram subsidiar a aquisição de fertilizantes químicos, instrumentos e maquinários agrícolas, além de construir infraestrutura para armazenamento da produção agrícola e para exportação (ROLLO, 2009).

Em 1966 houve a inauguração de trecho da Rodovia Pimenta da Veiga (MG-265), cuja extensão é de aproximadamente 12 quilômetros, conectando Nepomuceno à rodovia Fernão Dias (COELHO, 2012). Sua construção possibilitou o aumento da extração de renda da terra diferencial I pelos proprietários fundiários nepomucenenses, pois promoveu melhorias no atributo localização dos solos municipais. A proximidade em relação à Fernão Dias favorece o escoamento da produção agrícola, uma vez que a via liga importantes metrópoles nacionais, como Belo Horizonte e São Paulo (VILAS BOAS, 2016).

Os avanços nos transportes também ampliam significativamente a renda diferencial I (OLIVEIRA, 2007), fenômeno notado em Nepomuceno, pois melhorias na infraestrutura viária aumentaram a diferença entre o preço de produção em terras nepomucenenses e o preço social de produção, cuja medida é determinada pelo solo de pior qualidade, isto é, aquele que apresenta menores índices de produtividade e fertilidade natural (MARX, 1983). As melhorias no setor também colaboraram para o aumento da renda da terra diferencial II no município - a qual é obtida pela aplicação de técnicas e capitais nos solos - uma vez que os investimentos nos meios e vias de transportes melhoraram permanentemente a 
localização das terras nepomucenenses, diminuindo os custos para a distribuição da produção (HARVEY, 2013).

O sul de Minas Gerais vivia um momento de estagnação no setor agropecuário no final dos anos 1960. Neste sentido, os PRRCs possibilitaram a chegada de recursos financeiros, através da subsidiação de crédito, e a renovação da cafeicultura, atividade tradicional na região há mais de um século. Neste âmbito, a fertilidade dos solos sul-mineiros e o clima favorável ao cultivo da rubiácea foram fatores que colaboraram para que o Sul de Minas fosse a principal região responsável pela inserção dos PRRCs no estado (ANDRADE, 1994).

Até 1970, a cafeicultura sul-mineira predominou em solos de elevada fertilidade. As lavouras cafeeiras eram comuns em locais de topografia acidentada e com altitude entre 800 e 1300 metros. O consórcio de culturas envolvendo o café e outros gêneros, como milho e feijão, era usual na maioria dos municípios sul-mineiros e constituía uma maneira de aproveitar o espaço ocioso entre as ruas de plantio de café. Em Nepomuceno, existiam cafezais com mais de 80 anos de idade, cuja produtividade era diminuta (COELHO, 2012). Desta maneira, pode-se afirmar que o cultivo da rubiácea no sul de Minas Gerais era desenvolvido sem a aplicação intensa de técnicas e insumos oriundos da Modernização Agrícola. A partir de 1970, o cenário cafeeiro do sul de Minas foi alterado, pois áreas menos férteis foram ocupadas e o uso de fertilizantes químicos e agrotóxicos se disseminou, inclusive em Nepomuceno, conforme ilustra a Figura 03, a qual detalha o custo de produção da saca de 60 quilos de café, por item, no município durante a safra 1975-76.

Figura 03 - Itens do Custo de Produção (em Cr\$), por Saca de 60 kg, do Café no Município de Nepomuceno na Safra 1975-76

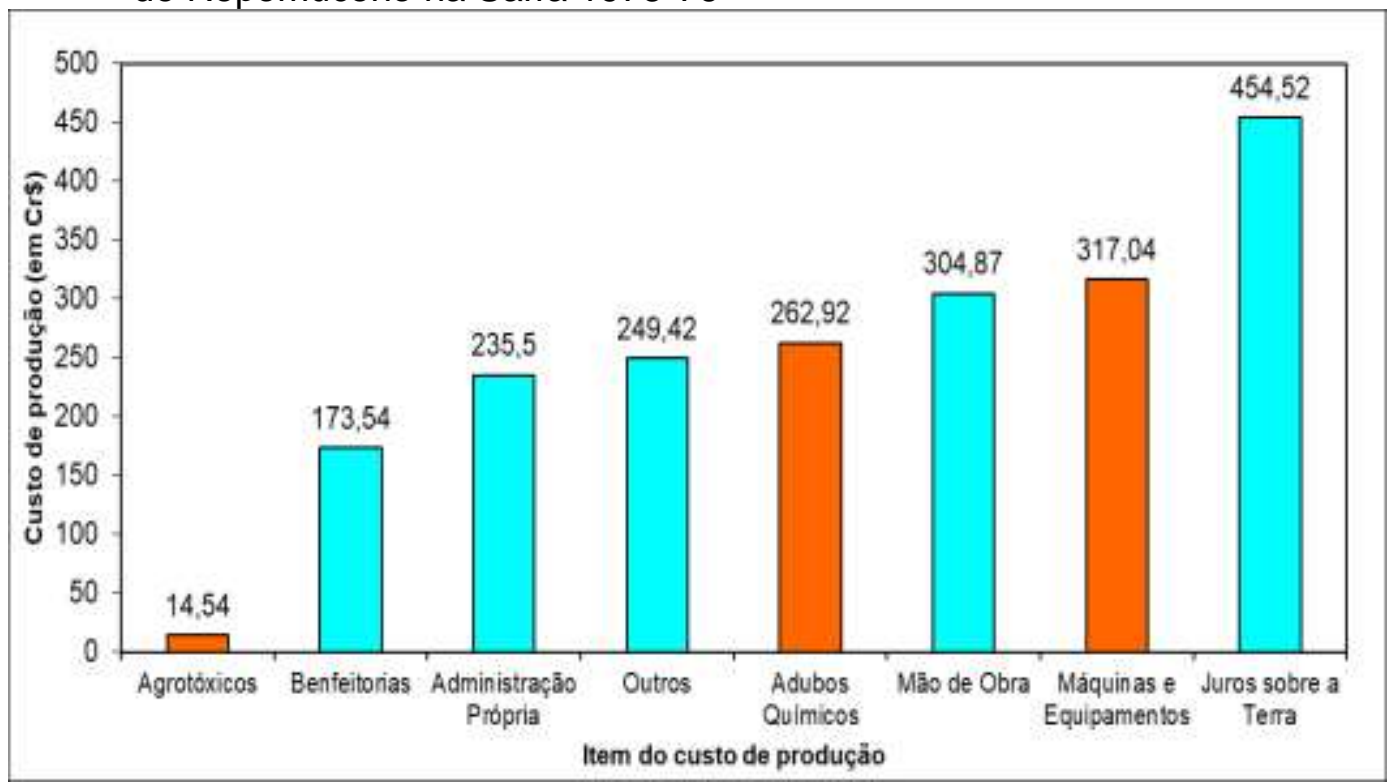

Fonte: Rufino (1977). 
No decênio de 1970, a aplicação de pesticidas nas lavouras cafeeiras se tornou comum, principalmente no combate a pragas, como a ferrugem. Neste contexto, em 1970, Nepomuceno foi o primeiro município sul-mineiro em que a doença foi constatada. Posteriormente, pesquisas evidenciaram que a ferrugem atingia a maioria das lavouras da região (COELHO, 2012; ROLLO, 2009). Neste ínterim, houve notável crescimento do uso de adubos químicos e pesticidas na cafeicultura mineira e sul-mineira (FREDERICO, 2017).

Durante a década de 1970, a expansão da cafeicultura foi estimulada pelo Estado no sul de Minas através dos investimentos fornecidos pelo IBC. À época, Três Pontas era o maior produtor de café da unidade federativa. Em decorrência dos incentivos estatais, o número de cafeeiros por hectare aumentou expressivamente. A geada de 1975 destruiu muitos cafezais nos estados de São Paulo e Paraná, contribuindo para a aceleração dos PRRCs nos municípios sul-mineiros e o crescimento da cafeicultura regional (COULIS, 2011; IBGE, 2016; FREDERICO, 2017). Após esse fenômeno climático, o cultivo de soja e de trigo cresceu em terras paranaenses, em detrimento da cafeicultura. Ainda neste decênio, muitos agricultores paulistas, em virtude dos riscos da cultura cafeeira, abandonaram-na, optando pela produção de outros víveres, como soja, cana-de-açúcar e frutas cítricas (ANDRADE, 1994).

Neste panorama, o IBC incentivou novas plantações nos municípios sul-mineiros, trazendo diversos avanços tecnológicos à cultura cafeeira, dentre os quais se destacam o maquinário agrícola e os insumos químicos, como os pesticidas. Ainda nos anos 1970, o órgão criou os Concursos de Produtividade Cafeeira com o intuito de elevar a produtividade dos cafeicultores no sul de Minas Gerais (COELHO, 2012). À época, alguns produtores nepomucenenses participaram destes eventos. De acordo com Andrade (1994), a expansão das lavouras cafeeiras em direção a Minas Gerais também se explica pelo menor preço da terra em comparação com outros grandes produtores de café da época, como Paraná e São Paulo. A tradição da mão de obra mineira e sul-mineira com o trabalho temporário nos cafezais e a considerável disponibilidade de força de trabalho favoreceram o crescimento de sua cafeicultura. Em Nepomuceno, a tradição secular do café no município e a importância econômica e social do período de colheita do café para seus habitantes corroboram as palavras do autor. Somente a partir da década de 1980 o estado de Minas Gerais se consolidou como o maior produtor de café do país, como evidencia a Figura 04.

Alguns fatores contribuíram para este fato, como as geadas em São Paulo e no Paraná, a inserção da cafeicultura em áreas do cerrado mineiro e a introdução dos PRRCs, um conjunto de medidas de cunho técnico aplicadas às lavouras cafeeiras mineiras. Criados pelo IBC, os PRRCs ampliaram a produtividade da cafeicultura através da inserção de tecnologias oriundas da Revolução Verde no processo produtivo. Contudo, a qualidade do 
café produzido se manteve estagnada, apresentando problemas no sabor e no processo de maturação (IBGE, 2016; PELEGRINI; SIMÕES, 2011; SOUZA; 2006).

Figura 04 - Participação média anual (em \%) das principais unidades federativas cafeicultoras no total de café produzido pelo Brasil no triênio 1981-1983

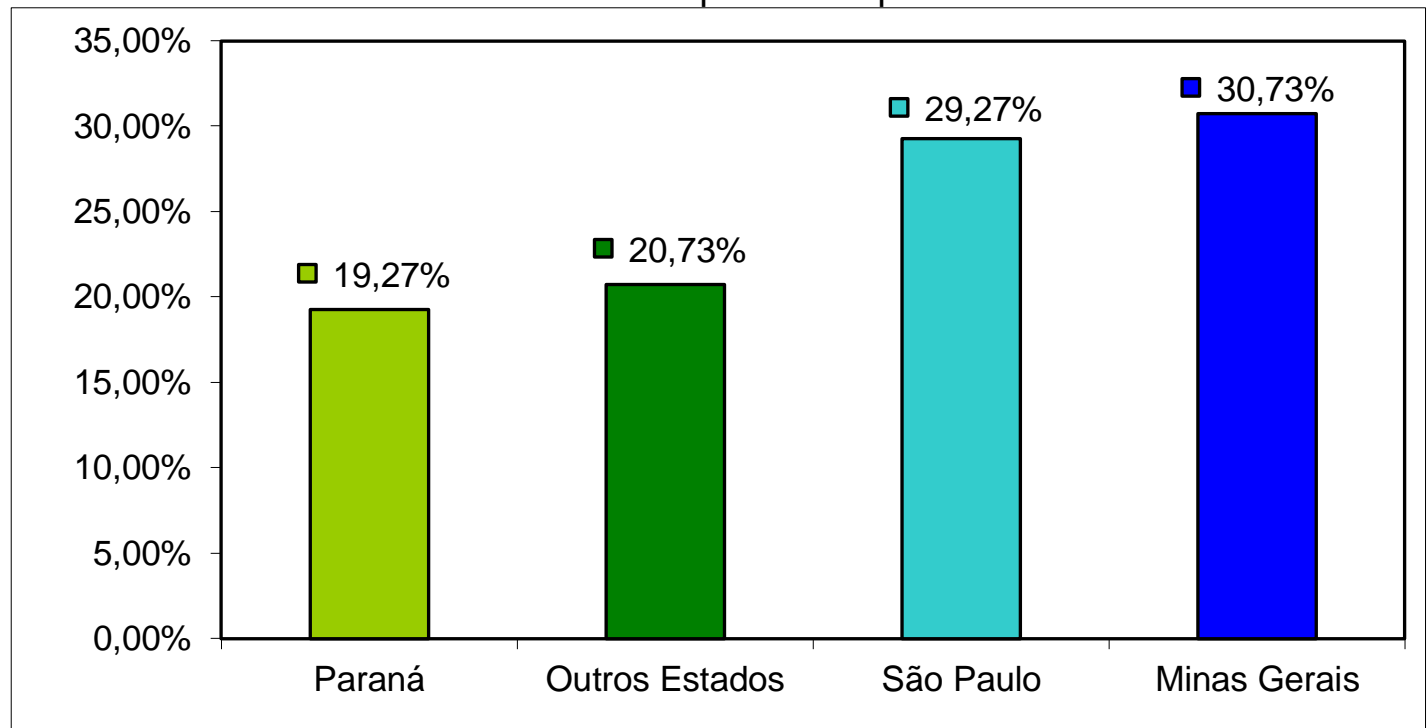

Fonte: Barone (2017).

O armazenamento e a torração inadequados, as adubações incorretas (as quais elevam o teor de nutrientes que minoram a qualidade do café), as doenças que assolam os cafeeiros e os longos períodos de estiagem são alguns dos fatores que avariam a qualidade do café produzido em território brasileiro (IBGE, 2016; FREDERICO, 2017). Além dos elementos que prejudicam os cafeeiros em território nacional, outros fatores contribuem para a baixa qualidade do café cultivado no município de Nepomuceno. A colheita semimecanizada com o auxílio da derriçadeira portátil não seleciona os melhores grãos, levando à coleta de grãos ainda verdes ou pretos e com outros defeitos, como a presença de paus, pedras e cascas. O manejo inadequado do solo e a falta de análise pedológica ou foliar também colaboram para a perda de qualidade de diversos cafeeiros no município (VILAS BOAS, 2016).

Muitos cafeicultores brasileiros e nepomucenenses não esperam o ponto de maturação do café para a colheita, pois aguardam a valorização da rubiácea nos mercados internacionais para vendê-la (IBGE, 2016). No Brasil e em Nepomuceno, o foco dos investimentos efetuados pela maioria dos cafeicultores é o aumento da produtividade dos cafeeiros, o que ocasiona a perda de qualidade dos grãos colhidos e a má reputação do café brasileiro em escala mundial (FREDERICO, 2017; MERGULHÃO, 2017).

Nos anos 1980, houve crescimento da participação de Minas Gerais e Espírito Santo na produção cafeeira nacional, em detrimento da cafeicultura paulista e paranaense (ANDRADE, 1994). No entanto, a centralização da cafeicultura brasileira promovida pelo 
IBC reduziu o vínculo entre os cafeicultores brasileiros e o mercado mundial. Assim, apesar da recessão experimentada pela cafeicultura em âmbito internacional na transição entre os decênios de 1980 e 1990, o IBC investiu maciçamente em pesquisa, ciência e tecnologia aplicadas ao setor, fomentando a produção cafeeira nacional (COULIS, 2011). Ao financiar a aquisição de insumos e maquinários agrícolas, o Estado brasileiro viabilizou a modernização da cafeicultura e das propriedades agrícolas nacionais, mas beneficiou as empresas oligopolistas atuantes nestes setores, como a Bunge, a Bayer, a Basf, a Heringer, a ChemChina, a Mosaic e a Yara, pois ampliou o consumo de suas mercadorias (ROLLO, 2009).

Para Marx (1983), o valor das mercadorias corresponde à quantidade de trabalho necessária para sua produção, considerando o tempo, a intensidade e a capacidade de trabalho médias da sociedade como um todo. Desta maneira, as inovações técnicas e seus progressos reduzem o valor das mercadorias, pois minoram o tempo (quantidade) de trabalho necessário à sua produção. Em suma, produz-se mais no mesmo quantum de tempo. Consequentemente, pode-se afirmar que o aumento da produtividade resulta na redução do valor das mercadorias. Conforme há variação da força produtiva do trabalho, a qual é determinada pelo grau de desenvolvimento científico-tecnológico, volume e eficiência dos meios de produção, destreza média dos trabalhadores e condições naturais (clima, fertilidade dos solos e topografia), entre outros fatores, o valor das mercadorias também é alterado, pois o tempo socialmente necessário à sua produção é modificado.

Assim, a Modernização Agrícola, a qual abrangeu também a cafeicultura brasileira, prejudicou os agricultores que não possuem meios para mecanizar sua produção, visto que a produtividade de suas lavouras se manteve praticamente estagnada, enquanto o valor dos gêneros agrícolas cultivados foi minorado. Em contrapartida, os grandes proprietários fundiários não foram tão lesados, pois possuem capital para aplicarem em insumos e maquinários voltados à produção. Deste modo, apesar da diminuição do valor dos gêneros agrícolas lavrados, como o café, esses produtores ampliaram a produtividade de suas terras. Através do aumento da produção e do consequente crescimento das vendas, compensaram as perdas causadas pela diminuição do valor venal dos víveres cultivados. Portanto, a modernização da cafeicultura brasileira, estimulada pelo Estado por intermédio do IBC, afetou principalmente os pequenos cafeicultores, colaborando para o seu empobrecimento e a piora da condição de vida de seus núcleos familiares.

No decênio de 1980, a cafeicultura alcançou expressivo destaque nas mesorregiões Triângulo Mineiro e Alto Paranaíba. A Revolução Verde, por meio de seu pacote de insumos tecnológicos, promoveu o uso de técnicas corretivas no solo, possibilitando a expansão da cafeicultura para as áreas do cerrado mineiro, cujos solos são ácidos e de diminuta fertilidade natural (IBGE, 2016). Por conseguinte, houve grande aumento da produção 
cafeeira de Minas Gerais entre 1980 e 1985, a qual praticamente triplicou no quinquênio (CARVALHO, 2013). Neste período, na microrregião de Lavras, onde está situado o município de Nepomuceno, o crescimento da cafeicultura foi superior ao constatado em todo o estado, conforme evidencia a Tabela 03.

Tabela 03 - Variação da Área Ocupada e da Produção Total de Café na Microrregião de Lavras no Período 1980-1990

\begin{tabular}{ccc}
\hline \hline Ano & Área Ocupada (ha) & Total Produzido (t) \\
$\mathbf{1 9 8 0}$ & 6.697 & 2.442 \\
$\mathbf{1 9 8 5}$ & 11.976 & 26.661 \\
$\mathbf{1 9 9 0}$ & 21.277 & 13.955 \\
\hline \hline
\end{tabular}

Fonte: Broggio, Droulers e Grandjean (1999).

Num ínterim de apenas cinco anos, a produção total da rubiácea na microrregião de Lavras decuplicou, enquanto a área total ocupada pelas lavouras cafeeiras quase duplicou. Houve grande aumento da produtividade cafeeira no quinquênio em questão, especialmente em virtude da adesão dos cafeicultores sul-mineiros às técnicas e aos insumos químicos provenientes da Revolução Verde, os quais promoveram o aumento da produção cafeeira regional, mas ocasionaram crescimento do desemprego rural e contaminação de alimentos, solos, recursos hídricos e animais, entre outros malefícios. Neste panorama, a atuação do IBC foi crucial à ampliação da produtividade cafeeira no sul de Minas Gerais, inclusive em Nepomuceno e municípios adjacentes. Andrade (1994) explica que o pacote tecnológico fornecido pelos PRRCs modernizou a cafeicultura sul-mineira, a qual era caracterizada pela baixa produtividade e por práticas arcaicas. Ademais, Coulis (2011) afirma que a facilidade de acesso ao crédito e a assistência técnica promovidas pelos PRRCs e pelas cooperativas favoreceram a mecanização da cafeicultura nacional e regional.

No entanto, com base na Tabela 03, observa-se que a quantidade de café produzida na microrregião de Lavras teve expressiva redução entre 1985 e 1990, apesar do notório aumento da área ocupada pela cafeicultura (BROGGIO; DROULERS; GRANDJEAN, 1999). A queda no volume da produção pode ser explicada, em partes, pela exaustão dos solos e pela bienalidade do café, fenômeno caracterizado por uma safra de alta produtividade sucedida por um ano com diminuição na produção total, no qual o cafeeiro despende energia para recomposição de sua estrutura vegetativa e, consequentemente, produz menos frutos (MERGULHÃO, 2017).

Segundo Frederico (2017), o período de profunda intervenção estatal na cafeicultura, compreendido aproximadamente entre 1960 e 1990, foi marcado pela regulação do mercado internacional de café através dos AICs e do setor cafeeiro nacional pelo IBC, e experimentou a cientifização da cafeicultura e sua inserção no meio técnico-científico. As 
técnicas provenientes da Revolução Verde foram introduzidas na produção cafeeira nacional, modernizando-a. No caso brasileiro, houve a gradativa substituição de espécies menos produtivas de café, como o tipo Bourbon, por outras de maior produtividade, como o Catuaí e o Mundo Novo, inclusive plantas geneticamente modificadas, muitas delas desenvolvidas por órgãos de pesquisa estatais e universidades públicas.

\section{ANOS 1990: DISSEMINAÇÃO DO NEOLIBERALISMO E SUAS CONSEQUÊNCIAS PARA A AGRICULTURA BRASILEIRA E SUL-MINEIRA}

A inserção do neoliberalismo na cafeicultura brasileira foi corolária do término dos AICs no ano de 1989 e do fim de diversos órgãos e instituições brasileiras relacionadas à produção e à pesquisa no setor cafeeiro. Os AICs eram pactos estabelecidos entre produtores e compradores de café no mundo inteiro, cujo intuito era deliberar sobre os estoques, os preços e as cotas de importação e exportação, entre outros aspectos. Em 1990, com o fim do IBC, o neoliberalismo adentrou a cafeicultura brasileira, promovendo alterações substanciais no setor. O controle estatal foi bastante reduzido e os produtores ficaram sujeitos às oscilações do mercado internacional. Durante o período de existência do IBC, o café brasileiro foi muito competitivo em escala mundial, pois a aliança entre Estado e cafeicultores possibilitou o atendimento à crescente demanda internacional. Após a extinção do órgão, as receitas geradas pela cafeicultura em território brasileiro e em Minas Gerais apresentaram expressiva redução (ANDRADE, 1994; FREDERICO, 2012, 2014; SOUZA, 2006).

Com a derrocada do Estado keynesiano e a consolidação do neoliberalismo, o mercado globalizado englobou diversas áreas produtoras de alimentos em cadeias produtivas internacionais (HARVEY, 2011, 2013). Ademais, a desregulamentação do mercado cafeeiro e o fim do IBC reverberaram na redução do valor venal do café, gerando uma severa crise para os pequenos cafeicultores brasileiros, os quais ficaram muito vulneráveis às variações do preço no mercado mundial (COULIS, 2011). Até o final dos anos 1980, os Estados atuavam na regulação do comércio e do preço do café. Nesta conjuntura, os maiores produtores armazenavam parte dos estoques de café, como modo de diminuir a oferta do grão no mercado internacional, com o objetivo de aumentar seu valor venal (FREDERICO, 2012).

Em momentos de recessão, os grandes cafeicultores podem aguardar uma ocasião de aumento do preço da rubiácea no mercado para vender sua produção, pois dispõem de capital suficiente para tal. Em contrapartida, os pequenos produtores ficam à mercê das oscilações do valor venal do café, uma vez que não possuem recursos financeiros para esperarem situações de alta dos preços internacionais da rubiácea. É inegável que os 
pequenos agricultores são os mais afetados, pois dependem diretamente da renda obtida com a venda do café para a satisfação de suas necessidades básicas. O café, assim como outros gêneros alimentícios, em âmbito nacional e mundial experimenta uma situação paradoxal. Enquanto os preços venais aos consumidores finais apresentam constantes acréscimos, há a diminuição gradativa nos valores pagos aos agricultores pelos grãos verdes. Com o advento do neoliberalismo e a diminuição da regulação estatal, as especulações envolvendo o café nas Bolsas de Mercados de Futuros ampliaram-se expressivamente (FREDERICO, 2014).

Na transição entre as décadas de 1980 e 1990, a cafeicultura brasileira vivenciou a consequência das modificações ocorridas na economia mundial. O término dos AICs em 1989 (FREDERICO, 2013) e a extinção do IBC em 1990 (BROGGIO; DROULERS; GRANDJEAN, 1999; COULIS, 2011) representaram, respectivamente, o ingresso quase integral da cafeicultura internacional e da brasileira nas cadeias produtivas neoliberais. No decênio de 1990, os preços da rubiácea no comércio mundial, cuja cotação é determinada nas Bolsas de Mercados de Futuros, atingiram os menores valores históricos, conforme atesta a Tabela 04, prejudicando severamente os cafeicultores em toda a superfície terrestre. As consequências da extinção dos AICs foram o aumento da concorrência entre os mercados produtores de café e a dissolução dos estoques, reverberando no decréscimo do preço do café em escala mundial (FREDERICO, 2014). Ademais, com a dissolução do IBC, a atuação de grandes cooperativas privadas na agricultura sul-mineira cresceu significativamente, sobretudo na cafeicultura, ocupando o papel institucional outrora incumbido ao órgão estatal. Destarte, as cooperativas monopolizaram a comercialização da cafeicultura no sul de Minas Gerais (COULIS, 2011).

Frederico $(2012,2014,2017)$ e Carvalho (2013) explicam que, na década de 1990, a adesão da cafeicultura ao neoliberalismo e o enfraquecimento do papel estatal neste ramo reverberaram no surgimento da cafeicultura científica globalizada, a qual está associada à concorrência capitalista e à procura pelo aumento da rentabilidade e da competitividade no mercado. Ante a financeirização da economia mundial e o ápice do capitalismo informacional, o comércio mundial de café é desregulamentado e a comercialização e o armazenamento de café são controlados pelas corporações oligopolistas transnacionais e multinacionais atuantes nos mercados internacionais.

Intimamente relacionada ao atual estágio da globalização, a cafeicultura científica globalizada é caracterizada pelo predomínio de políticas neoliberais, pela financeirização do mercado e pelo massivo uso de tecnologias de informação na produção e na comercialização da rubiácea. A ausência de intervenções estatais na cafeicultura ocasiona grande volatilidade nos preços pagos aos produtores, uma vez que há o aumento das especulações nos mercados futuros de café e da disputa entre as regiões produtoras. Além 
disso, as grandes empresas torrefadoras e as tradings intensificaram sua atuação no mercado cafeeiro em escala global (FREDERICO, 2014).

Tabela 04 - Preço Médio em US\$ das Sacas de Café Vendidas pela Cooxupé: 1981-1999

\begin{tabular}{ccccccc} 
Ano & Janeiro & Março & Maio & Julho & Setembro & Novembro \\
& & & & & & \\
\hline 1981 & 94,06 & 86,67 & 76,63 & 69,67 & 72,29 & 73,63 \\
1982 & 82,07 & 85,57 & 87,11 & 86,87 & 83,87 & 89,33 \\
1983 & 93,79 & 74,45 & 62,15 & 51,82 & 53,58 & 52,16 \\
1984 & 65,29 & 66,91 & 62,73 & 80,22 & 77,59 & 80,62 \\
1985 & 115,81 & 120,52 & 101,1 & 81,04 & 74,65 & 143,73 \\
1986 & 309,97 & 250,3 & 213,39 & 205,55 & 219,27 & 193,02 \\
1987 & 121,13 & 86,61 & 84,56 & 50,17 & 46,01 & 49,69 \\
1988 & 51,54 & 63,94 & 57,24 & 68,22 & 69,55 & 73,33 \\
1989 & 120,88 & 102,98 & 146,41 & 78,59 & 61,05 & 66,49 \\
1990 & 83,71 & 123,52 & 90,81 & 69,22 & 84,85 & 57,21 \\
1991 & 61,51 & 76,02 & 66,26 & 58,69 & 61,77 & 54,5 \\
1992 & 54,23 & 54,44 & 47,47 & 53,69 & 45,02 & 60,84 \\
1993 & 69,07 & 67 & 57,85 & 64,61 & 72,62 & 73,56 \\
1994 & 73,52 & 81,85 & 119,17 & 208,71 & 210,26 & 169,07 \\
1995 & 166,07 & 170,88 & 160,07 & 138,32 & 131,05 & 127,04 \\
1996 & 136,68 & 146,64 & 142,68 & 100,62 & 110,51 & 109,13 \\
1997 & 148,11 & 187,05 & 207,55 & 166,43 & 188,01 & 192,35 \\
1998 & 210,73 & 177,93 & 132,58 & 105,89 & 99,24 & 103,74 \\
1999 & 113,35 & 99,2 & 107,94 & 87,82 & 75,36 & 107,52 \\
\hline \hline
\end{tabular}

Fonte: Cooperativa Regional dos Cafeicultores em Guaxupé (2018).

Profundamente influenciada pelas leis de mercado e pelo meio técnico científicoinformacional, a cafeicultura científica globalizada é marcada pelo crescimento do setor de biotecnologia e pela intensa especialização produtiva, constatada pelo crescimento da produção de cafés especiais nos últimos anos. Neste cenário, a difusão dos cafés de atributos diferenciados foi uma solução encontrada para aumentar o preço da rubiácea no mercado e atender aos novos agentes do setor cafeeiro, como as empresas torrefadoras. Assim, houve aumento da produtividade e da busca por competitividade no mercado mundial. Com a extinção do IBC e dos AICs, o mercado financeiro passou a controlar os preços das commodities, entre elas o café, convertendo-as em espécies de derivativos, especialmente através da sua negociação nas Bolsas de Mercados de Futuros (BARONE, 2017; FREDERICO, 2017; MERGULHÃO, 2017).

No decênio de 1980 e no início dos anos 1990, houve expressivo deslocamento da produção cafeeira dos estados do Paraná e de São Paulo em direção a Minas Gerais. A estimativa para 1995 era de que o estado de Minas Gerais fosse responsável por mais da 
metade do cultivo do grão no país, enquanto o sul do estado produziria pouco mais de $30 \%$ de todo o café brasileiro (BROGGIO; DROULERS; GRANDJEAN, 1999). Neste ínterim, a produtividade da cafeicultura mineira apresentou significativo crescimento, muito superior ao das demais unidades federativas (IBGE, 2016; PELEGRINI; SIMÕES, 2011). Na transição para os anos 1990, Minas Gerais e Espírito Santo se tornaram os maiores produtores nacionais de café, embora algumas áreas em São Paulo e Paraná mantivessem expressiva produção (IBGE, 2016). Devido à crise na cafeicultura e à inflação que o Brasil vivenciava, alguns agricultores nepomucenenses migraram para estados do Norte e Centro-Oeste, buscando maiores rendimentos com culturas que apresentavam expressivo crescimento no país, como a soja.

Em 1994, grandes geadas afetaram a cafeicultura em São Paulo, no Paraná e no sul de Minas Gerais. A partir de 1996, os preços do café no mercado mundial apresentaram notório aumento, em parte devido aos eventos climáticos que assolaram os cafezais brasileiros no ano de 1994. Com o intuito de reerguer a produção cafeeira regional e nacional, as cooperativas incentivaram o replantio dos cafeeiros destruídos, através do intenso uso de maquinários e insumos químicos. Nota-se que houve expressiva variação da conformação geográfica de distribuição da produção cafeeira pelo território brasileiro, a qual apresentou expressivas modificações em comparação com o início do século XX, pois os Vales do Paraíba paulista e fluminense já não são as principais áreas produtoras de café do país. No panorama atual, Espírito Santo e Minas Gerais são os maiores produtores do grão, mas algumas áreas da Bahia, de Rondônia, do Pará e do Paraná também apresentam expressivas safras cafeeiras anuais (COULIS, 2011; IBGE, 2016).

$\mathrm{Na}$ América Latina, com a desregulamentação do setor cafeeiro e a adesão ao neoliberalismo após o fim dos AICs, alguns agricultores abandonaram a cafeicultura, enquanto outros optaram pelo consórcio ou rotação de culturas. A crise do setor cafeeiro nos anos 1990 ocasionou muitas migrações em toda a América Latina, aumento do desemprego no campo e a redução dos preços internacionais da rubiácea. O Brasil, contrariando a tendência continental e mundial, aumentou sua produção cafeeira no final dos anos 1990. Esse crescimento ocorreu devido a alguns fatores, como a falta de regulação estatal após a extinção do IBC; a expansão da cafeicultura para outras regiões, como o Cerrado mineiro e o Oeste da Bahia; e a intensificação do uso de fertilizantes químicos, máquinas agrícolas e praguicidas nas lavouras cafeeiras, cujo emprego ocasionou aumento da produtividade. Neste período, os preços internacionais do café alcançaram recordes negativos, a despeito do crescimento do consumo mundial de café (COULIS, 2011; FREDERICO, 2017).

$\mathrm{Na}$ década de 1990, o Estado brasileiro voltou a intervir na agricultura, inclusive na cafeicultura, através do Programa Nacional de Fortalecimento da Agricultura Familiar 
(PRONAF), do Fundo de Defesa da Economia Cafeeira (FUNCAFÉ) e de outros programas que financiam crédito rural a baixos juros. Além disso, o governo ampliou os investimentos na EMATER-MG e na Empresa de Pesquisa Agropecuária de Minas Gerais (EPAMIG), órgãos estaduais que auxiliam os pequenos produtores (COULIS, 2011). Em Nepomuceno, muitos cafeicultores aderiram ao crédito fomentado pelo PRONAF, inclusive contraindo dívidas decorrentes do pagamento destes empréstimos. A maioria dos financiamentos adquiridos com o PRONAF é empregada em investimentos na produção, como na compra de maquinário e de insumos agrícolas. Ademais, a atuação da EMATER no município é expressiva, fornecendo assistência técnica aos agricultores.

As atividades da cafeicultura científica globalizada e as práticas de períodos anteriores coexistem no sul de Minas Gerais nos tempos hodiernos (FREDERICO, 2017). No panorama nepomucenense, o qual se assemelha ao contexto regional, a produção cafeeira se enquadra principalmente nas características apresentadas pelo autor para o período marcado pela cientifização da cafeicultura e pelo predomínio do meio técnico-científico, pois há intenso uso de pesticidas, fertilizantes químicos e máquinas agrícolas, os quais reverberaram no aumento da produtividade. Em contrapartida, aspectos inerentes à cafeicultura científica globalizada, como o cultivo de cafés especiais, a aplicação de tecnologias de informação e a construção de bancos de dados referentes à produção para o monitoramento de riscos climáticos e intempéries, ainda são expedientes incipientes na conjuntura agrária nepomucenense.

\section{CONSIDERAÇÕES FINAIS}

Sob a hegemonia do keynesianismo, o IBC fomentou a inserção dos agricultores brasileiros na cafeicultura científica. Entre os decênios de 1950 e 1980, a cafeicultura sulmineira foi inserida no meio técnico-científico e passou a utilizar intensamente os insumos oriundos da Revolução Verde, como os agrotóxicos, os fertilizantes químicos e as máquinas agrícolas. Em diversos momentos, o órgão efetivou ações para regular a produção, os estoques e a venda de café. Ademais, estimulou a difusão dos cafezais pelo Sul de Minas e o surgimento de cooperativas privadas, as quais são muito atuantes na região.

O foco das ações estatais era o aumento da produtividade, algo constatado na instalação de uma filial da ACAR no município de Nepomuceno, a qual foi substituída em 1975 pela EMATER-MG. Por intermédio do GERCA e do SNCR, o Estado forneceu crédito para os cafeicultores adquirirem insumos agrícolas e majorarem sua produtividade. Já os PRRCs renovaram os cafezais dos municípios sul-mineiros, uma vez que promoveram a eliminação dos cafeeiros mais antigos e pouco produtivos - os quais eram comuns em 
Nepomuceno e no Sul de Minas Gerais até o decênio de 1970 - e sua substituição por novas plantas.

A despeito dos esforços estatais, o café brasileiro ainda é mundialmente conhecido por sua diminuta qualidade. Muitos cafeicultores sul-mineiros e nepomucenenses, em virtude de seu reduzido capital, comumente não esperam o momento de maturação dos grãos para colhê-los. Além disso, o uso da derriçadeira portátil no processo de colheita não seleciona corretamente os grãos, comprometendo a qualidade da produção.

$\mathrm{Na}$ transição entre as décadas de 1980 e 1990, o estado de Minas Gerais e, principalmente a região Sul de Minas, se consolidam como os maiores centros produtores de café do país. O predomínio do neoliberalismo diminui o papel do Estado no setor, fato representado pela extinção do IBC no Brasil e dos AICs em âmbito internacional. Assim, as cooperativas privadas assumiram o controle do setor cafeeiro sul-mineiro no decênio de 1990, ocupando a função outrora desempenhada pelo Estado. Sem a regulamentação estatal, a volatilidade dos preços internacionais do café, cuja cotação é definida nas Bolsas de Mercados de Futuros, foi ampliada, prejudicando principalmente os pequenos cafeicultores, os quais frequentemente não dispõem de capital para aguardar um momento de valorização da rubiácea para comercializar sua produção.

\section{REFERÊNCIAS}

ANDRADE, Rogério Geraldo Ribeiro de. A expansão da cafeicultura em Minas Gerais: da intervenção do Estado à liberalização do mercado. 1994. Dissertação (Mestrado em Economia) - Centro de Desenvolvimento e Planejamento Regional, Faculdade de Ciências Econômicas, Universidade Federal de Minas Gerais, Belo Horizonte, 1994.

ARAÚJO FILHO, José Ribeiro de. O café, riqueza paulista. Boletim Paulista de Geografia, São Paulo, SP, n. 68, p. 51-124, 1992.

BARONE, Marcela. Cafés especiais e salto de escala: análise do circuito espacial produtivo e dos círculos de cooperação dos cafés especiais do Sul de Minas Gerais. 2017. Dissertação (Mestrado em Geografia) - Universidade Estadual Paulista Júlio de Mesquita Filho, Rio Claro, SP, 2017.

BROGGIO, Celine; DROULERS, Martine; GRANDJEAN, Pernette. A dinâmica territorial da cafeicultura brasileira: dois sistemas de produção em Minas Gerais. Revista Território, Rio de Janeiro, v. 4, n. 6, p. 73-91, 1999.

CARVALHO, Ewerton Teixeira. Fluidez territorial e logística da produção cafeeira no Sul de Minas. 2013. 90 f. Dissertação (Mestrado em Geografia) - Instituto de Geociências, Universidade Estadual de Campinas, SP, Campinas, 2013.

CASTILHO, Fábio Francisco de Almeida. Entre a locomotiva e o fiel da balança: a transição da mão de obra no Sul de Minas (1870-1918). 2009. Dissertação (Mestrado em História) - Universidade Federal de Juiz de Fora, MG, Juiz de Fora, 2009.

COELHO, Antonio José Ernesto. Sul de Minas: excelência em café. Varginha: Edições Alba, 2012.

COOPERATIVA REGIONAL DOS CAFEICULTORES EM GUAXUPÉ. Cooxupé. Preço Histórico do Café. Preço médio das sacas de café vendidas na Cooxupé em US\$. 
Guaxupé, MG: Cooxupé, 2018. Disponível em: http://portalweb.cooxupe.com.br:8080/portal/precohistoricocafe.jsp. Acesso em: 15 jan. 2019.

FREDERICO, Samuel. Expansão da fronteira agrícola moderna e consolidação da cafeicultura científica globalizada no Oeste da Bahia. Boletim Campineiro de Geografia, Campinas, SP, v. 2, n. 2, p. 279-302, 2012.

FREDERICO, Samuel. Globalização, competitividade e regionalização: a cafeicultura científica globalizada no território brasileiro. GeoUSP: Espaço e Tempo, São Paulo, SP, v. 18, n. 1, p. 55-70, 2014.

HARVEY, David. O enigma do capital e as crises do capitalismo. São Paulo: Boitempo, 2011.

HARVEY, David. Os limites do capital. São Paulo: Boitempo, 2013.

IBGE. A Geografia do Café. Rio de Janeiro: IBGE/Coordenação de Geografia, 2016.

IBGE. Censo demográfico 2010: resultados do universo: características da população e dos domicílios. Rio de Janeiro: IBGE, 2010.

IBGE. Enciclopédia dos municípios brasileiros. Rio de Janeiro: IBGE, 1959. v. 26.

IBGE. Estimativas de população: 2019. Rio de Janeiro: IBGE, 2019a.

IBGE. Produção agrícola municipal: 2018. Rio de Janeiro: IBGE, 2019b.

VACA, Serginho T. A aurora de Nepomuceno: terceira parte. Folha Independente em Revista, Nepomuceno, MG, v. 9, n. 16, p. 13-17, 2015. Revista de aniversário.

VALE, Ana Rute do; CALDERARO, Rodrigo Alexandre Pereira; FAGUNDES, Francielly Naves. A Cafeicultura em Minas Gerais: estudo comparativo entre as regiões Triângulo Mineiro/Alto Paranaíba e Sul/Sudoeste. Campo-Território, Uberlândia, MG, v. 9, n. 18, p. 1 23, 2014.

VILAS BOAS, Lucas Guedes. Renda da terra agrícola em Nepomuceno-MG. Sociedade e Território, Natal, RN, v. 28, n. 1, p. 48-69, 2016.

WATSON, Kelly; ACHINELLI, Moira Laura. Context and contingency: the coffee crisis for conventional small-scale coffee farmers in Brazil. The Geographical Journal, London, UK, v. 174, n. 3, p. 223-234, 2008.

Recebido: maio de 2020.

Aceito: agosto de 2020.

\footnotetext{
'Este artigo é parte da tese de doutorado apresentada e defendida junto ao Programa de PósGraduação em Geografia da Universidade Federal de Minas Gerais no ano de 2019.
} 